\title{
A Study on Social Cognition of Wechat Virtual Society and Undergraduates
}

\author{
Lan Gang \\ Northwestern Polytechnical University, \\ Xian city, 710129
}

\begin{abstract}
With the rapid development of intelligent technology, in promoting social progress at the same time, its negative impact can't be ignored. Based on the strong connection - the weak connection social theory as the foundation, through the empirical analysis found that WeChat virtual community influence on college students' social cognition mainly reflects in: cultural cognition, increased the peer groups subculture identity, enhance the cultural participation; Moral cognition, positive and reverse construction, moral constraint feeling down; Action cognition, belonging to drift, the overall lack of ability to act. In order to improve college students' social cognition ability, we should strengthen the ideological and political education, with the core values guide the university students' social behavior; Create a good campus culture environment, innovation WeChat function; Establish WeChat intervention mechanism, pay attention to the social public opinion analysis on college students.
\end{abstract}

Keywords-WeChat; virtual community; social cognition; undergraduate

\section{INTRODUCTION}

As of the end of 201, micro-total number of users has reached 7.68 million, of which 500 million domestic users, 100 million overseas users [1]. The current WeChat of the main use of more than $50 \%$ of the age of $18-25$ years old, of which college students are the main user groups. The influence of micro-virtual community on the social cognition of college students based on Internet communication technology is an important subject worth thinking about.

\section{WECHAT VIRTUAL COMMUNITY CHARACTERISTICS, FUNCTION AND COMMUNICATION}

With the development of the Internet era, all kinds of physical space across the virtual community (Virtual community, VC) are increasingly active. The current virtual community has the following characteristics: the computer to communicate for the media to survive, thus excluding the real community; virtual community interaction is clustered, thus excluding the two interactive network services; community membership fixed, thus excluding the A public chat room composed of non-fixed people; community members must be able to feel the presence of other members after entering the virtual community [2]. Although the cognition of the characteristics of the virtual community is close to each other, the concept of "virtual community" is far from uniform, and different scholars have different definitions from different perspectives. Rheingold (1993) argues that virtual communities are "people who are primarily members of the computer network that communicate with each other and that they share a certain degree of knowledge and information with a certain degree of knowledge and information to a large extent Like the care of each other, thus forming the group. "This definition is widely cited by other researchers.

In addition to this is widely cited there is Porter (Porter, 2014) definition: "virtual community is a collection of individuals or business partners, the members of the collective have a common interest, in accordance with certain agreements and standards Communicate with each other, interact with each other or complete with technology as a medium, or partly by technical support.

Virtual community is the product of the Internet age, microvirtual community is also the product of the era of WeChat. The next definition of a virtual community is really difficult because it is a new generation of social media that supports cross-communication operators across the operating system platform through mobile Internet to quickly send free voice messages, videos, pictures and text, and its technical foundation also Still in the development process (technology platform has been $2 \mathrm{G}, 3 \mathrm{G}$ development to $4 \mathrm{G}$ ), its function is still in the extension (the current has opened up the QQ friends, mobile phone book, microblogging contact), as a hot social Network tools, the future development of WeChat to what extent, and now it is difficult to predict, the only sure it is rich in the connotation of the virtual community, expanding the boundaries of the virtual community to enhance the virtual community function, and become open virtual community and a main channel between the real communities. (See Table 1)

\section{STRONG CONNECTION - WEAK CONNECTION THEORY AND SOCIAL COGNITION}

Micro-virtual community in terms of thinking or from the life, has a profound impact on college students. Compared with the traditional SMS communication, WeChat more flexible, intelligent, and save tariffs, you can single chat, you can also group chat, you can chat with acquaintances, but also can chat with strangers, bringing the user a new mobile communication experience [3], greatly expanded the communication circle, the scope of communication, interpersonal communication has also changed. 
TABLE I.

WECHAT VIRTUAL COMMUNITY CHARACTERISTICS, FUNCTIONS, DISSEMINATION OF THE TABLE

\begin{tabular}{|c|c|c|c|c|c|}
\hline Characteristic & \multicolumn{4}{|c|}{ Features } & $\begin{array}{c}\text { Propagation } \\
\text { mode }\end{array}$ \\
\hline \multirow{4}{*}{$\begin{array}{l}\text { Immediate } \\
\text { Convenience } \\
\text { Extensive }\end{array}$} & $\begin{array}{l}\text { Bearer platform } \\
\text { function }\end{array}$ & $\begin{array}{c}\text { Communication } \\
\text { function }\end{array}$ & $\begin{array}{c}\text { Control } \\
\text { information } \\
\text { function }\end{array}$ & $\begin{array}{l}\text { Content analysis } \\
\text { function }\end{array}$ & \multirow{4}{*}{$\begin{array}{l}\text { Mainly one-on- } \\
\text { one } \\
\text { communication, } \\
\text { but also support } \\
\text { one-to-many } \\
\text { transmission }\end{array}$} \\
\hline & \multirow{3}{*}{$\begin{array}{l}\text { To smart phones, } \\
\text { PC for the body, } \\
\text { with Symbian, } \\
\text { Android, IOS } \\
\text { multiple versions } \\
\text { of the client }\end{array}$} & $\begin{array}{l}\text { Acquaintance } \\
\text { communication } \\
\text { circle: from the } \\
\text { phone directory, } \\
\text { QQ friends }\end{array}$ & \multirow{3}{*}{$\begin{array}{l}\text { Through the QQ } \\
\text { number can be } \\
\text { completed } \\
\text { WeChat, QQ } \\
\text { microblogging, } \\
\text { QQ mailbox, QQ } \\
\text { music and other } \\
\text { connections }\end{array}$} & \multirow{3}{*}{$\begin{array}{l}\text { Support offline } \\
\text { message } \\
\text { reception, through } \\
\text { the voice, text, } \\
\text { pictures, video } \\
\text { and other forms of } \\
\text { dissemination of } \\
\text { information }\end{array}$} & \\
\hline & & $\begin{array}{l}\text { Km circle: from } \\
\text { the "view nearby } \\
\text { people" function }\end{array}$ & & & \\
\hline & & $\begin{array}{l}\text { Stranger } \\
\text { Intercourse: Two- } \\
\text { dimensional code, } \\
\text { positioning, } \\
\text { shake, drift bottle, } \\
\text { LBS }\end{array}$ & & & \\
\hline
\end{tabular}

\section{A. Strong Connectivity - Weak Connectivity Theory}

As an important social theory model, strong connection weak connection theory has always been regarded as the theoretical foundation of micro-virtual community. Strong connection - weak connection theory (Mark S. Granovetter, 1973) uses four dimensions to measure the strength of interpersonal relationships: interaction frequency, emotional intensity, intimacy, reciprocal exchange. In real life, strong connections occur between people with strong similarities, such as colleagues, classmates, etc., these people to establish intimate relationship is more likely, but they have little difference between the information. Weak connections refer to those who are alienated, and the information they have is quite different. Therefore, it is possible to obtain information that is not available to you through a weak connection. This theory suggests that weak connections can facilitate the exchange of information among different groups.

WeChat virtual community set "strong connection" "weak connection" in one. First of all, WeChat friends mainly from the phone directory, $\mathrm{QQ}$ friends, this part of the crowd in the real life belongs to the acquaintance circle, so the connection between each other is "strong connection." Second, the WeChat two-dimensional code, positioning, shake, drift bottle, LBS function to expand the communication circle, strangers can be added as friends, this part of the interpersonal network is "weak connection." In these two interpersonal networks, the strong connection to the main body, but the weak connection can't be ignored, because only weak connection can reflect the unique characteristics of micro-virtual community.

\section{B. The Influence of Weak Connection - Strong Connectivity Theory on Social Cognition}

The strong connection that takes place in a similar attribute population Because the information is not very different from each other, the information circles are relatively closed, and in order to be consistent with the other members of the group, members often agree with or agree with the social perception, Or against. Through the weak connection to establish the relationship between the alienated crowds, each person master the information is quite different, the information circle is relatively open, showing the inclusion of different information. Different members will be based on their own specific social environment and their groups to access to the information to make a different understanding of different individuals, different groups can build their own meaning space, in the weak connection in the crowd due to lack of opinion leaders And the unity of voice, so the social cognitive diversity and lack of a fixed recognition.

\section{AN EMPIRICAL ANALYSIS OF THE IMPACT OF VIRTUAL COMMUNITY ON SOCIAL COGNITION}

In order to analyze the influence of micro-virtual community on the social cognition of college students, the author designed the questionnaire on the use of WeChat in college students, and tried to explore the factors and mechanism of micro-virtual community's social cognition. A total of 120 questionnaires were distributed in the form of random stratified sampling. The subjects were mainly college students in Hangzhou, 111 were collected, 4 were invalid questionnaires, $89.17 \%$ were valid questionnaires, $35.1 \%$ were boys in the survey accounting for $64.9 \%$. Through the data analysis, found the following characteristics:

\section{A. Cultural awareness, an increase of peer group sub-cultural identity, and enhance the sense of cultural participation}

As shown in Fig 1, the survey found that in the use of WeChat for many reasons, the expression of views and views $(21.32 \%)$ after the convenience of communication with friends (55.87\%), much higher than entertainment (16.62\%), make new friends (1.58\%) and other Factor (4.61\%). 


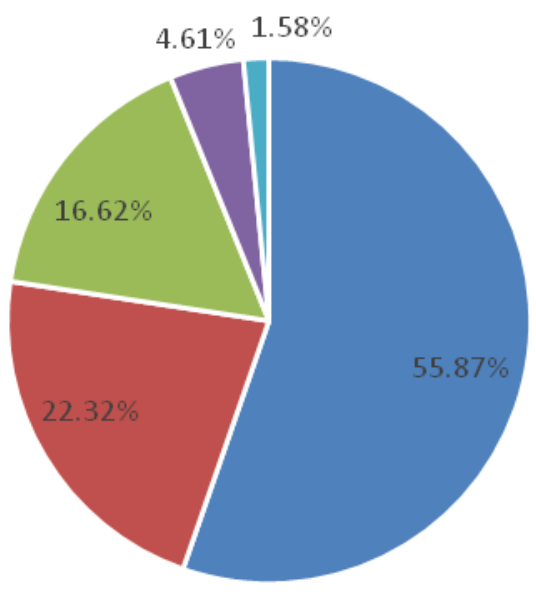

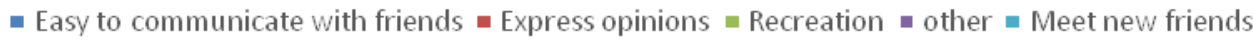

Fig. 1. Choose to use Wechat main reason

Further investigation of the contents of the opinion found that the unique language symbols and expression style are the main features of the micro-virtual community. Internet culture is a popular culture, so the sub-culture has a natural tolerance and acceptance.

Subculture is the symbolic system of the mainstream culture decoding, usually expressed the young people dissatisfaction and resistance to society, mainly for the production of their cultural symbols, to build a specific cultural space to show the difference with the mainstream culture, in the social and cultural system in the edge, the secondary position. Asian culture has a different value orientation with the mainstream culture, the mainstream culture to resist the subversive attitude, especially in the social existence of class differences and opposing circumstances or transitional social contradictions are more prominent when the young subculture will show a more intense of the deviant color [4]. The existence of subcultures can be seen everywhere in the micro-virtual community. The sub-cultural attributes of the virtual community are easy to attract the recognition of the rebellious consciousness and the avant-garde concept as the symbolic college students, and criticize the mainstream society. Admit a very popular fashion practice. Different members will be based on their own specific social environment and their own groups to access to the cultural information to make a different understanding of different individuals, different groups can build their own cultural space, any symbol is considered acceptable and meaningful. People's understanding of information is not the use of value judgments and ideologies, the freshness, irritation and the dominant position of the cultural form of the intensity of the confrontation of the information easier to cheer.

This cultural emotion on the one hand is to tap the cultural independence consciousness, on the other hand also cater to the psychological demands of unconventional. In the traditional political and cultural life, the young people, represented by college students, lack the vocal channel. The resistance to the dominant value system and the communication system mainly borrows all kinds of symbolic systems to turn the fierce confrontation to the moderate by dismembering, spoofing, borrowing and converting expression [5].WeChat virtual space belongs to other types of network virtual space, giving a sense of freedom and participation. This kind of "presence" and freedom, it is easy for the participants to fall into the "crowd carnival", here to express what is second, the key is that it has the style features so that each participant has a sense of ritual The change is called "subculture version 2.0 " by scholars[6].

\section{B. Moral cognition, positive construction and negative construction coexist, moral sense of decline}

The construction of social cognition in micro virtual community shows the characteristics of active construction and negative coexistence [7]. The so-called positive construction, refer to the virtual community in the virtual community of college students in the real social mainstream values and ideology under the guidance of production and dissemination of interactive activities. The so-called negative construction, that is, the construction of confrontational, confrontation type of identity derived from the different social status and conditions of the role [8]. (As shown in Fig 2)

The survey shows that $78.14 \%$ of the respondents said that in the WeChat communication often tell the truth, but there are $20.06 \%$ of people said that often tell lies. Further investigation of those who often say false statements will find that these people usually only happen when they communicate with strangers.

The semi-anonymity of the WeChat, the privacy and the absence of the subject's role provide a place of moral selfweakening, and many social control instruments such as legal, technical and moral are difficult to play their due role. In addition, the virtual community lacks the restriction and recognition of the real identity, and makes it possible for some college students to relax their moral restraint, moral relativism, 
moral nihilism generalization, ambiguity, and social responsibility in the virtual community. Has become a microvirtual community can't be ignored social phenomenon.
Up to $63.7 \%$ of the students said they had different degrees of deceit in contact with strangers, and most of them came from the identity of each other $(44.76 \%)$.

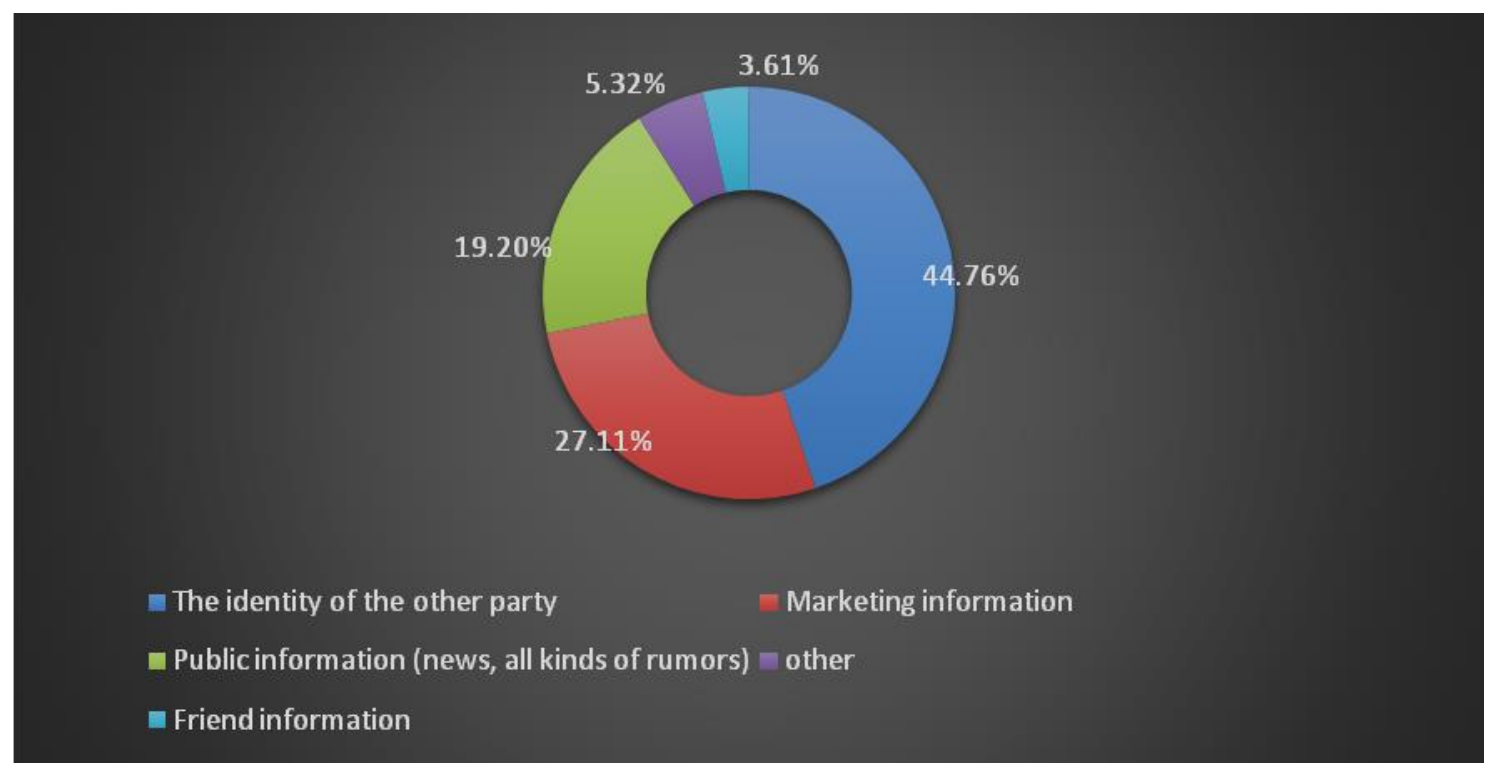

Fig. 2. What kind of information is most likely to be questionable

It is by the WeChat information cheating, many students choose to deceive the way to protect themselves or to deceive each other in the way to find themselves. It is difficult for this "self-protection" awareness of more judgments, some students may be deceived experience as a social practice class, warned himself into the community after the unfamiliar situation should take protective measures, but this protection But also hindered the interpersonal trust and from the strange population of information and emotional support.

Up to $43.10 \%$ of the students said they were concerned about the show, so many people in the form of show off their rich expression $(34.77 \%)$. In today's consumerism prevailing society, the identity based on consumerism refers to the need to use special goods to occupy and display to confirm. In order to get onlookers, response and discussion, the use of "show off their wealth" and other ways to find a limelight, won plaudits, become the most direct and the most efficient way.

"Container" theory that modern people in order to get rid of the lonely state is willing to contact with other people, but this contact is only outside the container collision can't be deep into the internal. People on the one hand eager to communicate, especially between strangers and no access to utilitarian communication, but on the other hand this exchange because of suspicious communication caused by interruption or communication blocked.

\section{Action awareness, a sense of belonging drift, the overall lack of mobility}

Bozeman argues that the uniqueness of the medium is that although it directs us to look at and understand things, it is often not noticed. It is no exaggeration to say that the media is more like a chronic poison, it makes you unknowingly dependent on it, when fully addicted, you know the pain and freedom of loss, but can't take any measures to remedy because it has penetrated your soul and bone marrow [9]. In the survey, $30.34 \%$ of the students said that if there is a day without a WeChat they will feel inexplicable panic, this WeChat era of interpersonal mobile Internet caused by "media dependence", also known as "WeChat control ", according to the degree of occurrence can be divided into eight grades: just look at the information and do not speak for the first stage, encountered their favorite only to return to the secondary stage, the rest of the time occupied for the three stages, working hours But also chatting for the four stages of the letter, do not rest at any time in the WeChat for the five stages, stay up all night to play WeChat for the six stages, but also brush the circle of friends for the seven stage, day and night to play WeChat for the critical stage[10]. Although the investigation is limited to the conditions can't "WeChat" level of the occurrence of the degree of investigation, but through the understanding of students on the WeChat time, found that the situation is not optimistic. 
TABLE II. DAILY WECHAT TIME STATISTICS TABLE

\begin{tabular}{|l|l|l|l|l|l|}
\hline $\mathbf{1}$ hour and below & \multicolumn{1}{|c|}{$\mathbf{3}$ hour } & $\mathbf{3 - 4}$ hour & $\mathbf{4}-\mathbf{5}$ hour & $\mathbf{5}-\mathbf{6}$ hour & $\mathbf{6}$ hour and above \\
\hline $17.86 \%$ & $36.9 \%$ & $20.66 \%$ & $18.33 \%$ & $5.35 \%$ & $0.90 \%$ \\
\hline
\end{tabular}

Can be learned from Table 2, often considered to spend more than 6 hours on microcredit, it can be considered more than four stages of the "WeChat control", and more than 12 hours, it belongs to "WeChat control" severe patients. WeChat addiction and network addiction both similarities, there are obvious differences. There are many types of Internet addiction, the academic community is basically summarized as follows: Internet pornography, Internet addiction, Internet information addiction, computer addiction. For young people in China, mainly for online games and online chat addiction and dependence [11]. WeChat addiction can be seen as an extension of Internet addiction, WeChat addiction is also included in the Internet addiction. WeChat addiction mainly manifested as excessive indulgence in the use of WeChat for interpersonal communication, and neglect and indifference in real life between the human communications. More than $70 \%$ of the respondents are most concerned about the diversity of communication means, in addition to the use of text, pictures, video, forward, comment, and share the function of communication channels diversified. However, over-reliance on WeChat to maintain interpersonal communication, in the real society in the face of real social relations, will feel nervous indifference, interpersonal relationship is not as good as WeChat, the formation of social barriers.

In the micro-virtual community, interpersonal communication is a kind of "human-machine-man" way of communication, which is easy to "quick" all kinds of social relations, but this kind of "quick" social relations foundation is not strong, Because the real society with the formation of social relations and the formation of emotions, feelings, consciousness and so on the screen, will inevitably lead to "quick" social relations swaying, suddenly, so the subjectivity of the occurrence of a degree of distortions and Alienation, the main body is not only faced with the same information as the object and the subject of the other, but also face the body and the soul with the self [12]. On the one hand people desperately and eager to express their own voice, on the other hand, few people quietly listen to the views of others, the shuttle in all kinds of social platform to express their views in the microvirtual community to determine the main self-existence means. When confronted with a disagreement or communication in virtual community, do not seek a solution to the problem, but instead perform another round of performance by exchanging the platform or re-applying for an account. This choice to avoid the solution, projected to real life is the lack of mobility and the reality of the contradictory turn a blind eye.

\section{Thoughts ON USING Micro-VIRTUAL COMMUNITY TO IMPROVE COLLEGE STUDENTS' SOCIAL COGNITION}

It is proved that it is necessary to grasp the development trend of the virtual community of micro-trust in colleges and universities, and to grasp the urgent desire of the college students' groups and the social participation, but also to prevent the negative impact of the virtual community.

The social meaning and social value of virtual community. Firstly, Strengthening the Ideological and Political Education of College Students and Guiding the Social Behavior of College Students with the Core Values. College students' subcultures can best reflect the ideological movement, social cognition and value of college students. Therefore, in the work of college students, we must take the initiative to occupy the commanding power of public opinion, and take the key crowd as the breakthrough and influence the "silent majority". For college students, their cultural behavior is more susceptible to the outside world, so should lock the key groups, such as class cadre, learn members, student members, etc., so that they "opinion leaders" identity with healthy positive view The wrong view of the living space, guide the surrounding world view, values, outlook on life, improve students 'media literacy, improve students' information recognition ability, learn to use WeChat to obtain useful information to resist the infiltration of bad information to enhance social awareness norms.

Secondly, to create a good campus culture environment, innovative WeChat function. It turns out that improving the moral quality of college students and cultivating the healthy personality of college students depend on the good campus culture environment. The campus culture environment is more free, open, equal, democratic, and more conducive to the students to play. In the construction of campus culture environment at the same time, should also focus on creating a campus WeChat environment. At present, colleges and universities have developed campus APP based on micro-voice interface, but more than the news of campus news and service information. In the future, we should also focus on the future development of the virtual community micro-culture of building socialism mainstream values. At present, the development of micro-credit function in colleges and universities is mainly focused on the exchange of information, and the guidance of micro-virtual community to college students' social cognition is far from enough. WeChat era must fully tap the WeChat function, enhance the micro-virtual community to attract students, so as to enhance the leadership of its social awareness. First of all, to enhance the virtual community virtual community "cohesion" ability, the use of WeChat to carry out peer education, design different topics to discuss, whether it is career planning and design, or "party" "PubMed" students interested in the topic, or the current major The views of the event, what students need to design what the theme, speak their minds, so that students in the free exchange of the environment to nurture growth. Secondly, we play the communication function of micro-virtual community, and organize the educational activities such as "micro-lecture" and "micro-speech" in micro-virtual community, and enhance the social recognition of college students in interactive 
communication and enhance the judgment and acceptability of college students.

Finally, the establishment of WeChat intervention mechanism, focusing on college students' public opinion analysis. It is difficult to control the development of virtual community, but it is always accompanied by social development, and can be regarded as "social subcommunication". In the micro-virtual community, the negative influence is sometimes far more than the positive information, colleges and universities should grasp the current social information, analyze its impact on the youth groups, firmly control the right to speak, good at grasp the opportunity to guide students to establish the correct values.

\section{CONCLUSION}

As a new social media, WeChat plays an increasingly important role in college students' interpersonal communication. It is necessary to note that the WeChat itself does not exist in the value of good or bad, how to rational use of both to avoid the adverse effects, but also play a positive role in social awareness, the key need to improve the rational use of microstudents ability and quality, thereby enhancing Social Cognition of College Students.

\section{REFERENCES}

[1] The number of micro-subscribers by 2016 [ EB/OL ] http://www.anfone.com/WXYHL/2016-6/53751.html

[2] Guo Maocan. Rules in Virtual Communities and Their Obedience Taking Tianya Community as an Example [ J ] , Sociological research, 2004 (2) : 105-108.

[3] Li Huaqiong. On the Innovation of Ideological and Political Education for College Students in the Times $[\mathrm{J}]$, School party building and ideological education, 2013 (5) : 63-65.

[4] Yang Cong. On the Youth Subculture in the Network [J] , Journal of China Youth College for Political Sciences, 2008 (5) : 53-56.

[5] Liu Ting. The Influence of Micro - transmission Environment on Youth Subculture [J] , Academic exploration, 2014 (10) : 81-84.

[6] Jiang Jianguo, Hua Maizi. Network "small fresh" culture of the show and charm], Modern communication, 2014 (7) : 13-17.

[7] Cai Qi. The Small Fresh Asian Culture in the Network Virtual Community [ J ] Journal of Hunan Normal University (Social Science), 2013 (6) : 125-132.

[8] Qiu Lin, Chen Taowen. Research on New Media Events [M] , Peking : China Renmin University Press. 2011.

[9] Neil. Bozeman, Zhang yan translation. Entertainment to death] , Guangxi Normal University Press, 2011.

[10] Lv Wenjing. The Influence of Micro - letter on College Students and the Corresponding Tactics, Today China Forum, 2013 (10) : 432435.

[11] Su Zhenfang editor Network Culture Research - Internet and Youth Socialization [M] , Social Science Academic Press, 2007.

[12] Ministry of Education, Ideological and Political Work Division . College Students' Network Ideological and Political Education [M], Peking : Higher Education Press. 2011. 